\title{
Imagen, realidad, modernidad y posmodernidad en España: 1936-1939. Una nueva aproximación metodológica
}

\author{
Manuel AnTÓN SALAS \\ Universidad Complutense de Madrid \\ Departamento de Historia del Arte III (Arte Contemporáneo) \\ arsenioanton@yahoo.es
}

\section{RESUMEN}

España, de 1936 a 1939, constituye un fenómeno per se que, a pesar de haber sido abundantemente analizado, sigue careciendo de un estudio que profundice en los mitos inspiradores de la matanza colectiva y de las distintas formas de revolución que tuvieron lugar en las fechas señaladas, así como las cosmovisiones a las que refieren dichos mitos. Para construir este estudio se propone una lectura semántica del imaginario de las cosmovisiones a partir de sus producciones socio-culturales, siendo éstas consideradas signos de un lenguaje cuyo desciframiento permitirá revelar los modelos originales de aquéllas.

Palabras clave: revolución y guerra civil españolas, cosmovisiones, mitos-mitologías, hiperrealidad, modernidad, postmodernidad, iconografía, semiología, imaginario, arquetipos, cultura y sociedad.

\section{Image, Reality, Modernism and Postmodernism in Spain: 1936-1939. A New Methodological Approach}

\begin{abstract}
From 1936 to 1939, Spain constitutes a per se phenomenon that, even though it has been copiously analyzed, lacks of a study that delves into the inspiring myths of the mass-slaughter and different forms of Revolution that took place through these years, as well as the worldviews to which the myths make reference. For building such a study it is proposed a semiotic lecture of the worldview's imagery based upon its socio-cultural products, being these considered as signs of a language whose decoding will reveal those worldview's original models.
\end{abstract}

Key words: Spanish Revolution and Civil War, worldview, myths-mythologies, hyperrealism, modernism, postmodernism, iconography, semiotic, imagery, archetypes, culture and society. 


\section{El estado de la cuestión}

Lo que acontece en España desde julio de 1936 hasta marzo-abril de $1939^{1}$ ha sido objeto hasta la actualidad de una copiosísima bibliografía, polémicas varias, debates de todo tipo, congresos, largometrajes... Mientras que la historiografía va limitando el terreno que queda inexplorado y al mismo tiempo que se desarrollan estudios especializados en el rescate de datos para construir historias locales (con intención historiográfica o de recuperación de la memoria), están a la orden del día todo tipo de mistificaciones, representaciones y construcciones culturales más o menos deliberadas. De la complejidad de lo acontecido en los casi tres años que nos ocupan se han ido aclarando, con el tiempo, los mitos más tópicos y los lugares comunes más divulgados, y poco espacio va quedando ya, afortunadamente, para revisionismos ${ }^{2}$. Al mismo tiempo, en los medios de comunicación y cultura actuales el tema sigue provocando enconadas discusiones que se hacen públicas desde el primer momento ${ }^{3}$ convirtiéndose en motivo generador de discusiones mediatizadas que, en la mayoría de casos, desinforman por exceso de celo mistificador. En ciudades como Madrid o Barcelona, la celebración de exposiciones, simposios, conmemoraciones, centenarios y demás eventos relacionados con la España de 1936-1939 forma parte de la oferta cultural habitual, y no son pocos los productos y reflexiones que se siguen haciendo fuera de España sobre el mismo tema. Se puede afirmar que, por un lado, los expertos van explorando terrenos cada vez más especializados del conocimiento y se van comprendiendo de forma cada vez más completa las cuestiones más complejas. Por otro lado, se transforma y renueva desde hace décadas, especialmente desde 1975, la memoria colectiva sobre el período a través de una imaginería poderosa, no siempre exacta o imparcial, desplegada en torno a obras de ficción, ensayos, debates reelaboraciones y por supuesto opiniones lanzadas a un espectáculo mediatizado continuo

1 Se va a denominar al fenómeno que nos ocupa intentando no encerrar la complejidad y contradicciones de su identidad bajo etiquetas insuficientes. El término "guerra civil española" resulta incompleto porque no expresa la intensidad ni la complejidad de los acontecimientos de la España de 1936 a 1939. Estos se comprenden a través del asunto bélico sólo parcialmente, pues aquello no fue sólo una guerra civil sino sobre todo un fenómeno surgido de las consecuencias de una primeriza revolución, un esfuerzo simbólicocultural de implicaciones internacionales e históricas y una clara intencionalidad de transformar la realidad española conocida hasta entonces. La guerra, fuera de simplismos, es el catalizador de las partes de dicho fenómeno. Un rol fundamental, pero no único. NOTA: a continuación se han incluido las ediciones españolas más recientes de los volúmenes citados, siempre que las haya, con la intención de ofrecer opciones generales de aproximación asequible para cada concepto que requiera de una nota al pie.

2 Y aún así, el Diccionario Biográfico Español (Real Academia de la Historia, XXX Vols., 2009-2012) y su contestación por medio de VIÑAS MARTÍN, Ángel (ed.), En el Combate por la Historia, Barcelona, Pasado y Presente, 2012, revelan la actualidad de la polémica y la necesidad de desmitificar el acercamiento a los acontecimientos. Especialmente en pp. 903-943, donde se comprueba la desgraciada actualidad de las falsarias construcciones franquistas.

3 Desde el conflicto ante la creación del Centro Documental de Memoria Histórica hasta la actualidad de las actuaciones del Juez Garzón, todos los medios han dado y siguen dando buena cuenta de debates y decisiones cuyo reflejo en la esfera pública se ha dado por sentado sin que se considere necesario restringirlo a la escena científica especializada. La proliferación de medios de comunicación de tendencia derechista (más o menos extrema, nunca moderada) y su eco en publicaciones afines es otra buena prueba del desequilibrado estado de la cuestión. 
que, se insiste, destaca por su ineptitud, su rechazo a la especialización y su caída en la franca falacia.

Es decir, lo que hay es un desequilibrio entre la forma de construir la historia de los hechos y las maneras de percibirlos y manejarlos, que hoy en día no se ha analizado con profundidad suficiente, está lejos de ser resuelto y es desde luego muy peligroso.

Y es que "cuando son los medios de comunicación y no los historiadores los llamados a sancionar las interpretaciones del pasado, el nivel cultural del país disminuye" A la hora de afrontar el peso del fenómeno español, se asumen y simplifican sin más sus facetas más complejas, olvidando que es precisamente en su desentrañe dónde se encuentran las explicaciones aún inéditas sobre las motivaciones de los españoles del 1936-39, que es casi lo fundamental que hay que aspirar a comprender. Incluso a día de hoy sigue siendo notoria la escasez de una historiografía social que produzca investigaciones sobre las mentalidades, las condiciones sociológicas y sus representaciones en la España de esos años. Existen estudios especializados ${ }^{5}$, pero no puede hablarse de una línea de investigación o de una metodología propia para el estudio del fenómeno "España: 1936-1939", desde la visión que ofrecen esas perspectivas. Más aún cuando uno de los aspectos más divulgados del caso español es el señalado aspecto sociocultural, actualmente otro lugar común, del que se ha divulgado con profusión el supuesto "romanticismo" del conflicto español, su papel de núcleo receptor de las energías del antifascismo internacional, la oposición cultural a la barbarie fascista...Un lugar común que sin embargo es el productor de algunas de las imágenes más persistentes en la memoria colectiva posterior y actual (el "miliciano" de Robert Capa, el Guernica de Picasso...). Y de hecho, en menos de tres años, supeditados a los acontecimientos generados por el conflicto, los españoles fueron capaces de elaborar un complejo y sofisticado aparato sociocultural incluso con una verdadera comunicación orgánica entre casi todos los grupos sociales. Pero los sucesos más tópicos del lugar común, otro ejemplo: el pabellón de la Exposición Universal parisina de 1937, son apenas la punta de un iceberg cuyo volumen sumergido es una vastísimo universo de creadores, intelectuales y agentes de toda condición, incluidos aficionados, no educados y anónimos, en continuo diálogo con las mentalidades de la sociedad que los inspira y los percibe. Iceberg que es el verdadero contexto del que surge el cliché y que debe entenderse como todo aquello que supone un esfuerzo por representar: el acto depositario de la naturaleza última de una sociedad determinada, en este caso la española del 36-39, cuya comprensión puede escapar del análisis his-

4 DONDI, Mirco, "La guerra civil italiana: de las armas a la memoria", en MORENTE VALERO, Francisco (ed.), España en la crisis europea de entreguerras, Madrid, Los Libros de la Catarata, 2011, p. 72.

5 EALHAM, Chris y RICHARDS, Michael (eds.), The Splintering of Spain. Cultural History and the Spanish Civil War, 1936-1939, Cambridge, Cambridge University Press, 2005; así como dos de los trabajos de BASILIO, Miriam, Re-Inventing Spain: images of the Nation in Painting and Propaganda 1936-1943, Tesis Doctoral, New York, Institute of Fine Arts, 2001; Idem, "Esto lo vio Goya, esto lo vemos nosotros. Goya en la Guerra Civil Española”, en MENDELSON, Jordana (ed.), Revistas, Modernidad y Guerra. Textos, Madrid, Ediciones Museo Nacional Centro de Arte Reina Sofía, 2008, pp. 99-116. Es mandatorio indicar, aunque no quepa reseñarlos aquí, que también vienen escribiéndose artículos centrados en estas cuestiones con cierta constancia y proliferación internacional. 
toriográfico al uso precisamente por la misma razón que hace de ello lo más elocuente. Porque reside en el territorio del imaginario.

\section{Crítica de la identidad del caso de estudio}

Este aspecto "cultural", claramente identificado, con más o menos espectáculo mediático, como una de las grandes especificidades de la España del 36 al 39, es resultado y no causa de la situación contextual. Todo aquello que configura la identidad del lugar común del fenómeno ${ }^{6}$ sobre lo que actualmente se continua reflexionando, investigando e incluso mistificando, es el producto de un contexto. Un contexto, el iceberg anterior, que resulta más revelador de los mecanismos mentales y simbólicos que justifican los hechos del fenómeno español, precisamente por subyacer. Sin caer en bizantinismos de huevo y gallina, podemos afirmar que es en el terreno de la representación subterránea, no erigida en iconografía histórica o de memoria (como si lo está, de nuevo, un Guernica), donde reside la verdadera identidad del contexto en su conjunto.

Y esta afirmación no es una obviedad porque hasta ahora no se ha efectuado un estudio de la relación entre las especificidades del fenómeno y este contexto, de las conexiones de los hechos con las concepciones y mentalidades de sus elaboradores. La pregunta clave -cuyo intento de respuesta es el objetivo de la tesis doctoral en la que se basa este texto- es hasta qué punto la representación devino realidad en su reflejo continuo de las "energías", por llamarlas así, de las masas que protagonizaron todo aquello. Y por supuesto cómo afecta, no tanto a lo que se denomina con mejor o peor fortuna la "cultura" de los españoles de aquellos años, sino sobre todo a las pautas de conducta sociales, sus actos derivados, los símbolos que manejan y bajo qué forma se manifiestan. Planteamientos cuya complejidad viene determinada en gran parte por las enormes ramificaciones que plantean las posibles respuestas, ya que sólo pueden obtenerse gracias a la combinación de distintas metodologías (historiográficas, sociológicas, representativas...). Independientemente de la mayor o menor universalidad del fenómeno español, obtener una respuesta, o al menos la aproximación a una explicación coherente para esas preguntas, contiene mucho de su comprensión global. Cómo orientar preguntas de esta naturaleza al análisis del caso de estudio, esa es la cuestión. Es obvio el inicio: en el estudio pormenorizado de los hechos históricos y sus interpretaciones, tanto las científicas como las mediáticas, lo

\footnotetext{
6 Buen ejemplo de esta asunción del cliché cultural es el título del epígrafe con el que la define Bartolomé BENASSAR: "Le Laboratoire du Siècle". El tópico lleva implícito muchas cuestiones, entre ellas la concepción de un "laboratorio" en el que, lógicamente, se experimenta con "l'expression de principes, d'idèes, d'articles de foi en concurrence sauvage". BENASSAR, Bartolomé, La Guerre d'Espagne et ses lendemains, Paris, Perrin, 2004, pp. 261 y ss. Basta para hacerse una idea de hasta qué punto está asumida la identidad particular del fenómeno español como un inmenso catalizador de prácticas de una importancia histórica lo suficientemente grande como para ser consideradas nada menos que "artículos de fe" que expresan nada menos que al Siglo [al siglo XX]. Sin embargo, al asumir se simplifica y no se presta la atención debida a las complejas contradicciones, diálogos y tensiones, tanto las internas del fenómeno como las surgidas en relación a las mentalidades de la población del que dicho fenómeno es un reflejo constante.
} 
mismo lo objetivo que lo tendencioso. Lo que debe tener prioridad absoluta es la búsqueda de los asentamientos sociales simbólicos (individuales y colectivos) de dichos hechos: el verdadero contexto cultural en su conjunto. Lo malo es que no se puede investigar la naturaleza de fenómenos tan radicales como el español de 1936-1939 sin dudar de la fraseología habitual de las obras de consumo y de la terminología canónica académica.

No se trata de una cuestión de memoria histórica sino de buscar una sedimentación de aquello que compone la memoria. Si bien es irrefutable y justo el rescate de recuerdos colectivos manipulados por décadas de franquismo, la verdad no reside tanto en el recuerdo sino en lo que encierra la representación realizada cuando aquello era experiencia y no memoria.

\section{Propuesta de ajuste de las categorías establecidas}

La propia expresión "guerra civil española" esconde la verdadera naturaleza del fenómeno, mucho más complejo de lo que deja entender. Tal vez sea una cuestión de tiempo transcurrido. Si bien a nivel historiográfico cada vez se adquiere un conocimiento más sofisticado de los acontecimientos, como hemos dicho, parece que aún nadie duda de las categorías halladas para describirlos. Es cierto que esa sofisticación conlleva un perfeccionamiento de los análisis académicos, pero aún la terminología de los expertos menos sospechosos de mistificaciones no abre nuevas vías de investigación. La propuesta consiste en comprobar que lo que hace de España: 1936-1939 un proceso específico no es la guerra civil sino todo lo demás ${ }^{7}$ : las formas que tienen los españoles de concebir, percibir y representar la totalidad de lo que están viviendo, de la cual la guerra sólo es una manifestación. Quizá el motor y la excusa, el medio, pero nunca fue la guerra el fin de ninguno de sus protagonistas o sus víctimas, sino un medio, propuesto por unos, impuesto a otros, para conseguir la construcción de la realidad a posteriori.

Esta apreciación, que puede resultar obvia hasta la redundancia no es superficial, puesto que ni los estudios especializados ni la jerga al uso han aclarado las formas

7 El debate sobre el número exacto o aproximado de víctimas encuentra sus discusiones más polémicas en los aspectos relativos a la represión, no al combate. Se da por sentada, tal vez con razón, la situación creada por la guerra per se, mientras los esfuerzos de los historiadores y, desgraciadamente, de los mistificadores, se encaminan a establecer números y juicios de valor sobre la naturaleza de los asesinatos cometidos más por la actividad represiva-terrorista que por la bélica. Sobre todo, como es obvio, por parte de los vencedores. La cantidad de tinta que el esclarecimiento o la mistificación de estos sucesos han hecho correr es sintomática de su importancia superior con respecto a los aspectos bélicos, o al menos, de la supeditación o dependencia de éstos a aquéllos. Pruebas hay de todos los tipos, desde el bizarro espectáculo mediático de un Pío Moa, que adjudica responsabilidades de forma aleatoria y se remonta hasta fechas anteriores a 1936 sin tratar de comprender en ningún momento, más bien al contrario, las complejidades contextuales del caso; hasta PRESTON, Paul, El Holocausto Español, Barcelona, Debate, 2011, cuyo título es ya elocuente: aunque etimológicamente resulte curioso, como se comprende en relación con el significado en torno a las atrocidades del nacionalsocialismo alemán, como se entiende en este reciente libro y en la conciencia colectiva actual (holocaustos armenios, ucranianos...), implica el asesinato en masa por medios y justificaciones que no son estrictamente militares, a pesar de que casi siempre surja en equivalencia o a raíz de una guerra. 
de concebir, percibir y representar la realidad española desde 1936 hasta 1939. No se trata de negar la terminología sino de ajustarla a la verdadera naturaleza de lo que pretende expresar, empezando por la propia expresión "guerra civil".

Más compleja es la continuación que se hace necesaria con respecto a dos términos cruciales, uno referido a la cuestión del "fondo" y otro a la de la "forma" del fenómeno español, es decir, ambos asentados en su identidad específica: ideología y propaganda.

Se suele dar por sentado, y así da fe ello tanto la elaboración científica como la representación ficticia, que de "todo" lo que compone la especificidad del fenómeno español, de ese iceberg contextual incompletamente definido como "salvaje concurrencia", surgen modelos históricos sobre ciertas cuestiones que se asumen como tales desde el momento que se identifican con la identidad de dicho fenómeno español. Para entendernos, del complicado conjunto de cosas, personas, hechos y circunstancias que fue España en esos años, se considera que lo que mejor lo identifica es precisamente la explosión de las ideas y sus manifestaciones, llamadas "culturales" o no, paralelas al hecho bélico: el imaginario. Ese muy relativo "laboratorio del siglo" en el que se da cita gente de todo el mundo para poner en práctica sus romanticismos, y su reflejo en iconos del peso actual de un Guernica, es algo que parece sobrevivir al tópico una y otra vez porque de hecho sí que define en gran medida al fenómeno español, separándolo de fenómenos similares en este o en otros países ${ }^{10}$. Los términos que mejor aluden a ello y que más abundan en la fraseología española de la propia época y en los análisis posteriores son "ideología" y "propaganda". Una vez se aprecian con detenimiento sus significados se comprueba su distancia con respecto a la naturaleza de la España de esos años, con lo que convierten en los objetos de revisión más urgente.

Para empezar, ambos tienen su significado absoluto y relativo (etimología, uso, connotación, denotación...) y no es cuestión de perderse demasiado por estos terrenos, por lo que deben considerarse en relación exclusiva con el caso de estudio, teniendo en cuenta además que ya dentro del fenómeno español sus significados son muy diversos y cambiantes.

Por lo que respecta a la ideología, en primer lugar, debe entenderse que su referente es ideal y se encuentra en el pensamiento: las ideas con las que uno o varios individuos reformulan teóricamente uno o más aspectos de su realidad conocida. En el momento en que se convierte en acto y la ideología dispone de una praxis, deja de significar puesto que el referente ya no es el pensamiento sino la acción ${ }^{11}$. Por

8 BENASSAR, Bartolomé (2004), op. cit., p. 261.

9 Ibid.

10 También es cliché la reacción de los intelectuales del mundo entero ante el caso español, la elaboración cultural dentro y fuera del país, la situación bélica vista a través de la cultura...todo lo cual se considera esencial para comprender la mayor parte de la especificidad del fenómeno. Con razón, pues aunque este estudio no se centra en los hitos culturales, no es superfluo señalar que suponen un caso tan excepcional en la historia de España que otorga identidad a unos años en los que las circunstancias no eran precisamente las más idóneas para la mejor expresión cultural.

11 Una diferenciación entre idea y acción que se encuentra en las raíces del pensamiento del siglo XX a través de un positivismo (relativo) que establece dicha diferencia atendiendo por primera vez a los contextos 
ello, sencillamente, creemos que no es demasiado ajustado referirse al conjunto de acciones, elaboraciones y representaciones que, aparte de la guerra, superpueblan el espacio-tiempo español de 1936-1939 como el producto de una ideología. Porque en el momento que la ideología se pone en práctica se vuelve tangible en mayor o menor medida (más o menos fáctica, más o menos simbólica). De modo que ya no es tal, sino que deviene cosmovisión, concepto propuesto por muchas razones ${ }^{12}$.

La principal es que "cosmovisión" no refiere a una idea o a un conjunto de ideas en un estadio mental sino que posee una doble naturaleza de pensamiento y acción (ver y representar) que le confiere identidad como estructura superior. Una estructura superior que crea un contexto, más o menos paradigmático, en el que surgen las ideas y en el que se realizan, una dinámica que supera la ideológica.

En el caso español, existen multitud de factores que justifican la utilización de esta palabra. Para empezar, la cacareada dimensión cultural, pues no sólo se refiere a la guerra, sino a unas formas de ver y representar el mundo, implícitas en el deseo de vencer la guerra, que escapan, gracias a su tangibilidad, del terreno ideológico y pasan a ser manifestaciones de la cosmovisión.

El fenómeno español supuso un brote tan rico y variado de representaciones -del cual el ejemplo del Guernica sólo es el aspecto divulgado, nunca el fundamentalque resultaría imposible de definir como manifestación ideológica, como mero pensamiento plasmado. Es inmensa la cantidad de productos, hechos, concepciones y elaboraciones que en la España de 1936-1939 se dotan de significado perceptible y valorado. Tanto que su enormidad sólo puede explicarse como respuesta a las aspiraciones totalizadoras de unas cosmovisiones que rebasan la ideología en cuanto se lanzan a dominar la realidad, a pesar de (o precisamente a causa de) la imposición de la guerra. Y ello mediante un imaginario y su correspondiente red de significados multiplicados en continua elaboración y difusión de pinturas, fotografías, carteles, discursos, esculturas, poemas, uniformes, insignias, decoraciones, tarjetas postales, canciones, grafitis...y también pautas de conducta, hábitos públicos y privados, valores sociales e individuales, usos del lenguaje, etc.

Todo ese resultante no es otra cosa que lo que el segundo término propuesto a revisión no acaba de definir, puesto que en ningún caso es consecuencia únicamente de una labor de propaganda ${ }^{13}$. Por muy asociada a lo político que se encuentre en el

sociológicos en los que surgen las representaciones de un determinado grupo en un determinado espaciotiempo. El clásico quizás sea TAINE, Hippolyte, aunque más Les Origines de la France Contemporaine: extraits, 4 vols., Paris, Hachette, 1947, que su Filosofía del Arte, Madrid, Espasa-Calpe, 1960. En relación con el concepto de ideología, y metido de lleno en el tiempo del tema de estudio: MANNHEIM, Karl, Ideología y Utopía: introducción a la sociología del conocimiento, México, Fondo de Cultura Económica, 2004. Para aspectos teóricos más generales, vid. FREEDEN, Michael, Ideologies and political theory: a conceptual approach, Oxford, Clarendon Press, 1998.

12 Sobre todo por su enjundia metafísica, que proviene del alemán Weltanschauung y designa, en definitiva, toda forma de ver y representar el mundo. Para una aproximación: DILTHEY, Wilhem. Selected Works, 2 vols., New Jersey, Princeton University Press, 2010.

13 Desde el primerizo e incompleto: GRIMAU, Carmen, El cartel republicano en la guerra civil, Madrid, Cátedra, 1979, hasta el riguroso y actual: CABAÑAS BRAVO, Miguel, Josep Renau. Arte y Propaganda en Guerra, Madrid, Ministerio de Cultura/CSIC, 2007, la mayoría de los estudios que incluyen análisis iconográficos despachan la mayoría de los casos de estudio como simples piezas de propaganda de lo que se 
aparato mediático actual, por mucho que tenga un gran sentido peyorativo, por muy pervertida que se encuentre en 1936 bajo los auspicios de un Dr. Goebbles, "propaganda" es un tipo de comunicación cuyo mensaje supedita la totalidad de su forma a la expresión de su irrebatibilidad ante un receptor. Esto es todo. Cuestión distinta es el proselitismo doctrinal o político, la fuerza expansiva de los medios de comunicación y cualquier intento de convencer de una realidad inexistente o de imponer un deseo en un receptor. Pero como tal, la propaganda es, en la España del 36-39, una forma de comunicación con unas características definidas, sujeta a una ideologización más o menos sofisticada, pero dependiente siempre de las premisas contextuales de la cosmovisión del grupo que controle dicha forma de comunicación.

Una fotografía de un niño español de 1937 rodeado de escombros, en la que se dispone un eslogan perfectamente político y que se hace tarjeta postal para difundirse por todo el país será propaganda -en efecto propaga un mensaje que puede ser, por ejemplo, ortodoxamente prosoviético- pero desde luego supera esta condición. Esa es la cuestión: investigar cuáles son los factores gracias a los cuales se produce esta superación que vuelve insuficientes las definiciones habituales. No todo el imaginario español de 1936 a 1939 es propagandístico, y el que sí lo es (nunca lo es exclusivamente) se merece un análisis que descubra su aspectos más específicos en cuanto a la elaboración, acción y efecto de lo que propagan. Es decir, en cuanto a sus relaciones con la sociedad que lo emite y lo recibe, como funcionan dichas relaciones, en qué se basan, cuáles son sus símbolos, sus signos, cómo se componen los códigos de su lenguaje... La fórmula, también tópica, de "arte-propaganda" para hablar de las imágenes de la España de esta época no sólo está lejos de explicar estas relaciones, es más, ni siquiera puede abarcar todas las imágenes elaboradas en esos años, "artísticas" o de otro tipo, con fines propagandísticos o sin ellos.

El único significado verdaderamente propagandístico que tiene el imaginario español de 1936 a 1939 es el etimológico: de Propaganda Fides, es decir, de la propagación de la $f e$. Por supuesto, esa fe no es cristiana, sino alusiva a la cosmovisión, cuya infalibilidad es concebida tan religiosamente como para que aspire a apropiarse de la realidad en su totalidad sin hacer ascos a la violencia. Algo que puede verse en los excesos de la revolución inicial y de forma más evidente en la imposición de la guerra por parte de las élites sublevadas.

\section{Hiperrealidad: pedestal y reflejo de la cosmovisión}

Con la intención de ofrecer una alternativa a "propaganda" para definir el tupido imaginario español de 1936 a 1939, es necesario entender la forma que tienen los españoles de ver y representar su realidad según se adscriban al comunismo, al fas-

consideran ideologías políticas, sin indagar en el sentido de un término que no puede seguir siendo concebido del mismo modo que en 1936, entre otras razones precisamente por su protagonismo en el lenguaje de una población en trance de asesinarse. Una de las razones de la elaboración de esta tesis doctoral es la ausencia de una investigación acerca de los códigos y funcionamientos de comunicación del imaginario español de 1936 a 1939, mucho más allá de su pertenencia o no a premisas propagandísticas concretas. 
cismo, al anarquismo, al socialismo revolucionario o al fundamentalismo católico (incluso al parlamentarismo demócrata). Eso es la cosmovisión en cuanto al caso de estudio. Porque la guerra se hace con la permanente intención de erigir un "nuevo orden", un nuevo mundo que acabe con el anterior. Esto es: con la intención de dar la victoria a una cosmovisión. El objetivo es ni más ni menos que la reordenación total de la realidad, al menos en "todos" los ámbitos de su percepción y acción. Eso es lo que conecta, por una parte, la aplicación española de esos ismos con el concepto de Weltanschauung y lo inserta en una sociedad real del siglo XX. Por otra, vuelve pertinente la identificación de cosmovisión y fe que acaba de hacerse ${ }^{14}$. Lo que pretende la cosmovisión es cambiar la realidad en todos sus ámbitos, tanto los fácticos positivos, por decirlo así, como los simbólicos, sociales, psicológicos o de cualquier tipo. Es probable que sea esa filosofía de la acción el componente que convierte a estos ismos en cosmovisiones plenamente modernas. Aunque los tópicos engañan, ese componente activo dinamizó ideologías que de otro modo resultarían obsoletas, caso del pensamiento monárquico, alfonsino o carlista, lo mismo da si se comparan con el falangismo.

Volviendo a la naturaleza de las cosmovisiones, ésta se manifiesta a través de sus aspiraciones de control absoluto de la realidad, a través de los actos que convierten (subvierten) aquello que implican. Por eso se ha afirmado desde el principio que es este fenómeno y no la guerra lo que determina la profunda transformación que sufre la realidad percibida y vivida por los españoles en esos años. Porque sólo se concibe contestar la sublevación fallida, hacer la guerra, en nombre de una determinada cosmovisión. Es más, es un hecho conocido que la diferencia entre unas y otras cosmovisiones causó más de un problema simbólico y práctico en la zona republicana, zanjados a veces con violencia ${ }^{15}$. Para el combatiente más consciente, "de lo que se trataba era de cambiar el régimen capitalista y crear una sociedad más justa ${ }^{16 "}$. Ello implica derribar una cosmovisión preexistente (la versión española del capitalismo bajo su forma más o menos democrática basada en el libre mercado y la propiedad

14 La consideración de las cosmovisiones occidentales surgidas en el paso del siglo XIX al siglo XX como religiones seculares y los conflictos violentos surgidos de ellas es un tema que excede las pretensiones de este artículo, que no ha dejado de ser señalado una y otra vez tanto por sus protagonistas como por analistas posteriores de toda clase. En BRENAN, Gerald, El Laberinto Español: antecedentes sociales y políticos de la guerra civil, Barcelona, Backlist, 2009, (la edición española más reciente, original de 1943), ya se encuentran conectadas partes de la cosmovisión anarquista española con un cierto milenarismo, aunque hoy pueda afirmarse que es como mínimo una comprensión parcial del asunto. Véanse las investigaciones de ESTRUCH, Joan, Historia Oculta del PCE, Madrid, Temas de Hoy, 2000, sobre mitología comunista de cierta inspiración cristiana. De obligada lectura: véase MICHAUD, Éric, La estética nazi. Un arte de la eternidad, Buenos Aires, Adriana Hidalgo editora, 2009 (edición francesa, 1996). Por supuesto, el fundamentalismo católico de ciertos grupos y su componente atávico, así como el famoso concepto de "cruzada" no entran en esta relación, pues son formulaciones estrictamente religiosas, no religiones secularizadas, como las cosmovisiones en forma de ismos. Es "la imputación a lo espiritual" que Pierre Vilar relaciona al valor simbólico-social y a supuesta modernidad de algunos de los valores en los que se asientan las cosmovisiones. A pesar de cierta ambigüedad en sus planteamientos. VILAR, Pierre, La guerra civil española, Barcelona, Crítica, 2000, pp. 32-38.

15 MARTÍN RAMOS, José Luis (ed.), Els fets de maig, Barcelona, El Viejo Topo, 2010; HERNÁNDEZ SÁNCHEZ, Fernando y VIÑAS MARTÍN, Ángel, El desplome de la República, Barcelona, Crítica, 2009.

16 MERA SANZ, Cipriano, Guerra, Exilio y cárcel de un anarcosindicalista, Madrid, Confederación Sindical Solidaridad Obrera, 2006, p. 32. 
privada). Por otra parte, el carácter latente de las cosmovisiones anteriores al 18 de julio de 1936, y la espontaneidad de su surgimiento posterior, coloca a la población ante una consumación anunciada a la que se le impone una guerra. Esa premeditación influye con no poca fuerza en el mantenimiento, por parte de las cosmovisiones, de sus aspiraciones totalizadoras de la realidad. La guerra obligada es, primero, el medio para realizar la cosmovisión, más tarde un obstáculo y por último la causa de su imposibilidad. No hay que olvidar que las aspiraciones del "nuevo orden" nunca dejaron de motivar los deseos de victoria y que algunas consecuciones de la revolución de primera hora se mantuvieron vigentes en la zona republicana hasta el fin de la guerra, resistiendo los envites de control de los gobiernos de Negrín (en materia simbólicamente interesante, sobre todo: instrucción pública, la cuestión agraria...).

A fin de cuentas, los medios que se necesitan para "cambiar el régimen capitalista", ¿no son mucho más complejos que los que se requieren para hacer una guerra? Lo que se entendía en 1936 por "régimen capitalista" no es sino una compleja superestructura de la que surgen naciones, sistemas económicos, sociedades enteras...Se trata entonces de sustituir una cosmovisión por otra, algo que no puede consumarse si no es afectando a todos los ámbitos de la realidad. Una realidad que ha surgido de la propia cosmovisión y alude constantemente a ella (como estructura superior) y que no se puede subvertir sin tratar de abarcarla totalmente, de totalizarla convirtiendo "cualquier elemento de la vida cotidiana, de las rutinas diarias (...) en ideológicamente significante, en objeto de debate y de revisión constante", hasta implicar "las estructuras familiares, la convivencia doméstica, las relaciones sexuales, los hábitos de consumo y de higiene, los ritos comunitarios de celebración, de duelo y funerarios, la redefinición de los sentimientos, de la lealtad, la amistad, el amor... ${ }^{17}$ ".

Por tanto: derribo de lo real conocido y viejo, fundación de lo real experimentado y nuevo. Sustitución imposible si no es totalizadora, esto es, si no consigue erigir una paralela y reflectante hiperrealidad.

\section{Manifestaciones de hiperrealidad como base (lógica) de la cosmovisión}

Lo primero: la "hiperrealidad" tiene significado en cuanto a la multiformidad con la que soporta el peso de las cosmovisiones del fenómeno español. Por supuesto, lo primero sería más bien definir y acotar lo que se entiende por "realidad" tanto en la España del 36 como en la actualidad. Pero no es pertinente indagar ahora en el sentido epistemológico, metafísico, etcétera, del término, ni en sus relaciones con el Ser ni en nada de lo que define lo que tal vez sea la espina dorsal del pensamiento filosófico. Claro que tampoco es cuestión de limitarse a considerar "real" a lo fáctico positivo,

17 FERRÉ VÁZQUEZ, Rosa, "El tiempo se acelera", en La Caballería Roja. Creación y poder en la Rusa Soviética de 1917 a 1945, catálogo de Exposición (7 de octubre de 2011 al 15 de enero de 2012), Madrid, La Casa Encendida, p. 48. La cita muestra el mecanismo totalizador como clave de la identidad de una cosmovisión activa en cualquier proceso revolucionario. En este caso, el bolchevique ruso, cuyas premisas influyeron directamente sobre no pocas de las propuestas españolas. ¿Y qué decir del fenómeno bajo la férula nacionalsocialista, cuya feroz totalización de su realidad es uno de sus mayores distintivos? 
por utilizar la jerga al uso, ni es necesario (relativamente) atender a lo "preexistente" o a "lo que está por existir", al menos desde la España de 1936-1939. Para esta investigación, es realidad toda aquella superestructura organizadora, jerarquizadora y canónica que, sujeta a una percepción consciente e inconsciente por parte de grupos o individuos, desarrolla a su vez estructuras que lo sostienen tanto por medios prácticos/sensoriales como por medios simbólicos/conceptuales ${ }^{18}$. Su relación con la cosmovisión es evidente: ésta determina las percepciones de los que construyen todo aquello que, en su nombre, se llamará "realidad".

Porque no hay fenómeno más cambiante en la España de esos años, precisamente por esta convergencia de cosmovisiones activas (enfrentadas a una guerra obligada). En primer lugar, de hecho, la propia "realidad" de lo que unos y otros grupos percibían como "España".

Ante el fallo del golpe de estado de julio del 36, se sublima en cosmovisión lo que era ideología y se lanza a imponer por todos los ámbitos $s u$ realidad, para dominarla toda. En ese acto de hipnosis colectiva ${ }^{19}$, la hiperrealidad es necesaria como aparato que lo sostenga, en lo tangible y en lo simbólico, otorgándole un contexto y un reflejo permanente, de manera que pueda establecerse un territorio de realidad paralelo a la realidad que está creando la cosmovisión. Un aparataje que se mueve por dos frentes.

En primer lugar, en la enorme significación que poseen hechos, actos y fenómenos que antes de julio de 1936 no eran reales y que de pronto lo son al surgir de estados particulares de percepción entre la sociedad, generados por la totalización de las cosmovisiones y su radical efecto en lo que hasta ese momento se conocía como "realidad". De la noche a la mañana, como quien dice, conceptos, hechos y valores que hasta ese momento la mayoría de la población pasaba por alto o daba por sentado se subvierten completamente. El funcionamiento las relaciones sociales, la vida cotidiana... pasan a tener un significado totalmente nuevo. Conceptos, hechos, valores cuyo significado antes se asumía, o que no significaban (aparentemente) nada, a partir de 1936 se invisten de significados bien ostensibles, incluso decisivos sobre la vida y la muerte. Es decir, la praxis de la cosmovisión vuelve a la realidad mucho más perceptible a través de una red de significados subvertidos y novedosos. Y lo hace tanto en fenómenos originados por las circunstancias como en aquellos que, preexistentes, se confieren de significaciones nuevas. De ello se deduce que la cosmovisión necesita de una hiperrealidad primero por apoyo etimológico: una superioridad o exceso en lo que es real, por tanto también en sus significados y formas de percibirse, elaborarse, representarse...

En segundo lugar, la hiperrealidad sostiene, justifica, explica y refleja la cosmovisión mediante la producción de un número impresionante de manifestaciones del imaginario. El exceso de lo real empieza por atrofiar los significados y continúa atro-

18 Sobre un fenómeno tan inabarcable, limitados por los terrenos que demarca la investigación y con la intención de no caer en eclecticismos ni análisis superficiales: SCHOPENHAUER, Arthur, El mundo como Voluntad y Representación, Madrid, Alianza, 2010; RUSSELL, Bertrand, Misticismo y lógica y otros ensayos, Barcelona, Edhasa, 1987; BERGER, Peter L. y LUCKMANN, Thomas, La construcción social de la realidad, Buenos Aires, Amorrortu, 1967; WITTGENSTEIN, Ludwig, Tractatus lógico-philosophicus, Madrid, Alizanza, 1975; Idem, Aforismos, cultura y valor, Madrid, Espasa, 1995.

19 COWLES, Virginia, Looking for Trouble, London, Hamish, Hamilton, 1941, pp. 77-80. 
fiando las percepciones hasta el colapso, mediante representaciones en cantidad delirante y en constante alusión a la cosmovisión. La hiperrealidad en este segundo estadio lo es por la superabundancia de estímulos y referencias generadas por la operación totalizadora - la apropiación de lo real- que culmina cuando las percepciones de todos los que viven la realidad en construcción convergen en la especificidad de la cosmovisión. No se puede construir un "nuevo mundo" de otra manera, salvo por imposición violenta, claro está. Desde el lenguaje hablado y escrito hasta la vestimenta y la decoración pública, no queda un solo espacio de lo real que no se supedite a un imaginario cuyo referente es la cosmovisión. De modo que su conceptos no paran de reiterarse, en un proceso que transforma la realidad extendiendo sobre su totalidad dicho imaginario, disgregado en tal infinidad de elaboraciones que acaba formando una realidad paralela, es decir, superpuesta.

Para los españoles de 1936, por un lado, están los significados más ponderables de la nueva realidad en construcción (cosmovisión), que aunque dinámicos, novedosos y peligrosos de interpretar, no dejan de ser medianamente mesurables por mucha tensión psicológica que generen (cuestiones logísticas, lógicas de combate...) Por otro lado, la superabundancia de un imaginario que invade y pretende adueñarse del espacio público y privado (este último violentamente alterado, considerablemente disminuido por las circunstancias): carteles, prensa, revistas, álbumes, folletos, exposiciones, concursos, novelas, relatos, ensayos, postales, fotografías, composiciones musicales, películas... y aún más revelador: periódicos murales, paneles decorativos, banderas, pancartas, mosaicos, letreros, canciones populares, guiñoles, insignias, actos públicos, grafitis, conferencias, emisiones radiofónicas...y, todo aquello que Pérez Contel denominó con humildad "propaganda de bulto" ${ }^{20}$, o sea elaboraciones escultóricas, decorativas o en forma de paneles u objetos (tribunas para discursos, letreros tridimensionales, mobiliario, trampantojos, figuras y carrozas para desfiles...) que tienen en común un carácter esencialmente efímero.

Total: que todo este imaginario se apropia, literalmente, de la realidad por invasión $^{21}$ y crea una propia, en perpetua referencia a la cosmovisión y a veces muy distanciada de las circunstancias reales, según se supedite a una mayor o menor "propaganda". Por ejemplo: un texto periodístico que describe un hecho bélico con optimismo y literatura cuando sus lectores (entre ellos los combatientes) saben que no ha constituido más que un fracaso y un gasto de vidas humanas. O mejor todavía: un cartel que expresa su fe en una victoria que la población sabe imposible.

En cualquier caso, la operación es de gran escala: la inserción de una realidad referencial en la realidad en construcción, para sostenerla y garantizar la infalibilidad de la cosmovisión como nuevo orden.

20 PEREZ CONTEL, Rafael, Artistas en Valencia 1936-1939, Valencia, Generalitat Valenciana, 1986, pp. 223 y 369.

21 El grueso del imaginario es el corpus principal de objetos de estudio para la tesis doctoral que inspira este texto y se encuentra en archivos y bibliotecas de todo el país. Vistazos generales pueden echarse sobre: MENDELSON, Jordana, Revistas y Guerra 1936-1939, Madrid, Museo Nacional Centro de Arte Reina Sofía, 2007; PEREZ CONTEL, Rafael (1986), op. cit.; en el más reciente de CABAÑAS-BRAVO, Miguel (2007), op. cit., elementos efímeros en pp. 90-98, 132-140 y 154; GAMONAL TORRES, Miguel Ángel, Arte y política en la guerra civil española. El caso republicano, Granada, Diputación Provincial, 1987. 
Ahora bien, dicho imaginario e manifiesta tangible e intangible a través de objetos efímeros, libros, obras de arte, canciones, actos, eventos... ¿entra a formar parte de lo que se conoce como "cultura" 22 ? Dicho de otra manera: si en el espacio demarcado por el reiterado tema de "la guerra civil y el arte español" caben hechos como, otra vez, el Guernica, ¿cuál es el "lugar" de este tupido imaginario hiperreal en la historia de la "cultura" española?

Resulta curioso cómo, generadas por el mismo fenómeno, se mantienen en la memoria colectiva imágenes singulares que gozan de fama internacional mientras se carece de un análisis sobre el complicado universo que conforma el grueso de su corpus. Y aún más curioso el hecho de que en la literatura especializada sobre el fenómeno español se continúe separando los conceptos "arte" e "imagen" sin tener demasiado en cuenta que las circunstancias que vive España trastocan absolutamente, si no es que desmantelan, toda la estructura habitual de lo que se conocía como "mundo del arte" 23 . Sobre esa relación mal enfocada entre lo que se entiende como "arte/ cultura" y el imaginario identificado, así como sobre cuál es el análisis más adecuado para este último, es necesario detenerse con calma, dada la evidente complejidad de sus planteamientos.

\section{Identidad estética del fenómeno español. Imaginario, no "Arte" (en la sociedad española)}

Afirma Jaime Brihuega en un texto ya clásico que "socavada la infraestructura de la producción artística y desbordados en su totalidad los planteamientos ideológicos a los que ésta hubiese podido servir de base, a partir de 1936 y hasta el final de la guerra, nos encontramos con un conjunto de fenómenos de cultura visual con una independencia suficiente como para constituir un capítulo aislado de nuestra historia cultural ${ }^{24 "}$. Ese conjunto, el imaginario, lo concibe como un cúmulo de "objetos, sucesos y, más aún, de géneros visuales que requieren para su estudio incluso una metodología propia, tanto para su fase de producción como para su proceso de consumo ${ }^{25}$ ".

De la cita llaman la atención dos cosas: primero, la actualidad de sus afirmaciones. Escritas hace más de treinta años, apenas un lustro después de la muerte de Franco, la bibliografía posterior ha sido incapaz de refutarlas porque no sólo no ha podido dar

22 Sin insistir todavía en si es "alta", "baja", "popular" "elitista", de "buen gusto" o de "mal gusto", etc.

23 Es decir, la red de personas, hechos y fenómenos que controlan la producción, difusión, conservación, promoción, venta y crítica de lo que en un espacio-tiempo determinado se llama "arte". Todas las implicaciones del término artworld y la teoría institucional del arte, hoy en día lo suficientemente extendida, ya sea corroborada o refutada, tal y como se define originalmente en DANTO, Arthur, "The Artworld", en The Journal of Philosophy, 61 (19), octubre de 1964, pp. 571-584; así como en DICKIE, George, "Defining Art", en American Philosophical Quarterly, vol.3, n 6, julio de 1969, pp. 253-256; citados ambos en FURIÓ GALI, Vicenç, Sociología del Arte, Madrid, Cátedra, 2000, p. 52.

24 BRIHUEGA, Jaime, Las vanguardias artísticas en España. 1909-1936, Madrid, Itsmo, 1981, pp. 148149.

25 Ibid., pp.148-149. Cursivas propias. 
con una metodología propia, sino que ni siquiera ha abierto una línea de investigación que se desmarque de los hitos tradicionalmente mimados por el espectáculo cultural consensuado hasta el día de hoy (y de nuevo: el Guernica).

Segundo, la importancia de considerar el imaginario producido en esos años, que también se concibe a base de elaboraciones de lenguajes muy distintos, capítulo aparte en la historia "cultural" española. Esta identificación del imaginario como fenómeno parte de una valoración de su cantidad y diversidad de manifestaciones, que es precisamente el punto de partida de esta investigación y la base de los análisis sobre la naturaleza del tema de estudio. A partir de ahí es de dónde se propone que el fenómeno se conforma como tal gracias a la construcción de hiperrealidad que soporta y expande la cosmovisión.

Pero el caso es que es un hecho: "el arte y la guerra civil española" (igual que "la cultura y la guerra civil española") constituye un tema per se, que ha generado multitud de documentos y eventos, al mismo tiempo que el imaginario localizado carece de una aproximación que lo sitúe en el lugar de la "cultura", española o de más alcance, que le corresponda. Ese desequilibrio es la clave para entender el problema, sino es el problema mismo. La tendencia de las investigaciones de separar el "arte" de la "cultura", visual o de cualquier tipo -o al menos de obtener del panorama solamente lo considerado "arte"- denota que no se ha resuelto. Una tendencia que se manifiesta, como es lógico, en la ausencia de estudios sólidos sobre el fenómeno que supone el imaginario. Está además tiene la dificultad añadida de ser uno de los conceptos empleados con más reiteración para referirse al fenómeno español. Sin que sea necesario incidir en las nociones que se han tenido y se tienen sobre "alta" y "baja" cultura, ni en la perteneciente más o menos a las "masas" frente a la que pertenece a una "élite" ${ }^{26}$, sólo se considera en cuanto a la convicción de Brihuega acerca del imaginario como hito en la historia "cultural" española y la poca atención que, no obstante, se le ha dedicado. Nos detenemos en el concepto con brevedad, única y exclusivamente por dos razones: para resaltar la desaparición en España de las habituales categorías en las que se dividía antes de 1936 y para revelar la pervivencia de las mismas en los análisis culturales sobre el fenómeno español que se han hecho hasta el día de hoy. No interesa tanto a que "tipo" (casi es más ajustado decir "clase") de "cultura" pertenece el imaginario como saber que éste no se encuentra incluido apenas en lo que se ha considerado hasta ahora "cultura" española de 1936-1939. Que además sigue siendo analizada en base a esas dicotomías: bajo/alto, popular/educado, etcétera.

$\mathrm{Y}$ es que es inútil incidir, aparte de lo mencionado, en la espinosa cuestión acerca de qué es o no "cultura" (tan espinosa como la de qué es o no es "arte") porque consideramos el fenómeno español como un todo conectado orgánicamente en el que las categorías dicotómicas dejan de tener preeminencia sobre las que surgen bajo la acción de la cosmovisión. Alta, baja, de masas o de élites, aunque de cada una

\footnotetext{
26 Una buena aproximación que no ha envejecido en absoluto: RAMÍREZ DOMÍNGUEZ, Juan Antonio, Medios de masas e historia del arte, Madrid, Cátedra, 1976. También, de actualidad: ROJAS MIX, Miguel, El imaginario: civilización y cultura del siglo XXI, Buenos Aires, Prometeo, 2006; ECO, Umberto, Tratado de semiótica general, Barcelona, Lumen, 1977; Idem, Apocalípticos e Integrados, Barcelona, Lumen, 1968; GUBERN, Roman, Mensajes icónicos en la cultura de masas, Barcelona, Lumen, 1974.
} 
de estas "clases" de cultura ocurra de facto en España las categorías no se ajustan a la realidad de 1936-1939. Por lo tanto, dejan de tener valor de norma (basado en el peso de la tradición, de "lo que es habitual") y pasan a ser, simplemente, nociones (que rara vez se tienen en cuenta). Sólo de la mano de las organizaciones oficiales o alternativas, siempre con muchos matices en cuanto a las formas hasta entonces usuales de elaboración, difusión y recepción de la cultura (las ocasiones más conocidas, explicables solamente por la intención de ofrecer una imagen, de cara al extranjero, de una situación española "normalizada"). Algo que tampoco es sólo propaganda y que no acabó con las nuevas prácticas de la cosmovisión y la persistencia de su hiperrealidad ni siquiera durante los gobiernos, supuestamente de ordenamiento burgués democrático, de Negrín.

Pero, sobre todo, lo fundamental es que esas dicotomías y diferencias son, en primer lugar, construcciones sociales impuestas de autoridad relativa, tanto si se aplican al estudio del fenómeno español como si se incluyen en un método de conocimiento general; en segundo lugar, y como tales, son clasificaciones unívocas que han servido para exagerar la percepción y el conocimiento de unos hechos aislados hasta convertirlos en falsarios paradigmas muy alejados de poder reflejar con exactitud el complejo, rico y multiforme contexto general. Mientras se mantiene oculta la trascendencia del imaginario total, que es con lo que verdaderamente conecta la sociedad española en su conjunto, precisamente por su constitución de hiperrealidad permanente y por su influencia constante sobre las percepciones. Sólo últimamente comienzan los especialistas a rescatar panoramas de conjunto para obtener de ellos conclusiones socioculturales, y muy poco a poco. Lo normal ha sido, por su parte, extraer nombres propios y trayectorias individuales del complicado imaginario español. Incluidos los casos en los que aquellos considerados "artistas" trabajaron al lado de amateurs o creadores anónimos. Es un campo de estudio en el que cada vez se van recomponiendo más hechos y fenómenos con mayor sentido, pero hasta el día de hoy escasean los estudios o análisis sobre el delicado aspecto "cultural" del fenómeno español que no se ocupen exclusivamente del "arte" y "los artistas" que éste inclu$\mathrm{ye}^{27}$, dejando de lado la enormidad del imaginario completo, tan inmenso como para ajustarse al concepto de hiperrealidad. Es cierto que dentro del imaginario hay obras de arte, e incluso obras de artistas que por lo demás no contribuyeron demasiado al fenómeno global. Otros artistas hasta dieron su vida por los acontecimientos. Pero si es un hecho que a partir de julio del 36 deja de haber una situación normalizada o acostumbrada para lo que se entendía hasta entonces como "institución arte" ¿por qué no se ha admitido todavía la supeditación de la obra de los "artistas" de 1936 a 1939 a los complejos fenómenos que caracterizan dichos años? Y más aún, ¿por qué no se ha demarcado todavía el lugar de aquellos que sin ser artistas y a veces ni siquiera aficionados se pasaron los casi tres años de conflicto creando y representando?

27 Prueba de ello es que los análisis que han ido apareciendo, salvo excepciones, tienen el común denominador de los nombres propios para sus títulos. Nombres de artistas que ya lo eran antes de 1936, a pesar de que su obra a partir de esa fecha no puede entenderse sin lo que supone el imaginario para el concepto de "arte", desde el colapso de sus instituciones y funcionamientos hasta su adsorción en el mecanismo de las cosmovisiones. 
Desde que el profesor Brihuega admitiese el trastoque de los mecanismos habituales del "mundo del arte", nadie se ha ocupado de observar el resultado de ese desmantelamiento. No se ha analizado aún el imaginario como tal, ni cómo construye la hiperrealidad, ni sus prácticas en la anulación de la situación previa, ni sus propuestas de nueva realidad basada en una cosmovisión. Circunstancias fundamentales para entender un fenómeno cuyo contexto de aparición, como puede deducirse, tampoco ha sido objeto de atención de las investigaciones.

\section{Una postmodernidad (inconsciente y previa): contexto del imaginario}

Evidentemente, no es baladí, o al menos no pretende serlo, la afirmación de que el contexto "cultural" español de 1936 a 1939 es en cierta medida postmoderno. Es una etiqueta que hay que matizar, empezando porque de 1936 a 1939 el término no se conocía como tal. Aunque tampoco es necesario establecer una genealogía del término ni del de "modernidad". Para lo que afecta a la España del 36 al 39, se entiende como la construcción normativa de la historia occidental, que designa aquellas manifestaciones consideradas culturales que representan el proceso surgido de la tensión entre el individualismo y la masificación como forma de existencia durante un siglo XIX especialmente acelerado por continuas transformaciones en todos los ámbitos de lo real. O más en concreto, la "cultura" occidental que atestigua ese proceso, incluyendo la necesaria dinámica de derribar y proponer cosmovisiones que conlleva semejante tensión, así como sus consecuencias sociológicas, psicológicas y fáctico-prácticas ${ }^{28}$. La historiografía artística y la crítica de arte canónicas han ido asentando el exitoso término de "vanguardia" para designar los productos que mejor y de forma más completa, a veces incluso deliberadamente, reflejasen dicha tensión, dejando fuera del discurso aquellos otros surgidos a pesar de ella. Es decir, entender los "ismos" como formas válidas de "cultura", el resto de manifestaciones y representaciones como meras consecuencias.

Ahora bien, esta construcción hace mucho tiempo ya que se cuestiona y se refuta, empezando por la existencia del propio término post-modernidad. Pero hay que señalar que la historiografía del arte sobre el fenómeno España: 1936-1939 sigue filtrando sus consideraciones bajo esta mirada. Lo que se afirmaba, unas páginas más arriba, sobre la exagerada individualización en la reconstrucción del fenómeno español no responde más que a una visión de los acontecimientos anclada en una pertinencia y validez de un concepto de "vanguardia" que cada vez es menos creíble. Por muchas razones, principalmente dos: en general, ya están demostrados los mitos que

28 BLOM, Philipp, Años de Vértigo. Cultura y cambio en Occidente. 1900-1914, Barcelona, Anagrama, 2010; CHILDS, Peter, Modernism. London/New York, Routledge, 2000; ECO, Umberto, Los limites de la interpretación, Barcelona, Lumen, 1992; EVERDELL, William R., The First Moderns: Profiles in the Origins of Twentieth Century Thought, Chicago, University of Chicago Press, 1997; FRASCINA, Francis y HARRISON, Charles (eds.), Modern Art and Modernism: a Critical Anthology, London, The Open University/ Harper and Row, 1982. 
construyó la modernidad ${ }^{29}$. Y en particular, ha permitido la pervivencia de categorías parciales y ha fomentado que el imaginario producido en la España del 36-39 se haya mantenido casi oculto. Por lo tanto, no es una cuestión sobre la "vanguardia" española (en guerra), sino de la relación entre la "modernidad" como paradigma culturalexistencial y el imaginario español, cuyos elementos llamados "vanguardistas" son sólo hechos canonizados como más y mejor modernos. En ningún caso comunican el verdadero estado de la cuestión, perceptible en el conjunto formado por la coyuntura de surgimiento del imaginario, su relación con la cosmovisión y su apoyo en la hiperrealidad. Con lo cual, cuanto más conocida es una figura o personaje artístico español, menos cabida tiene en esta investigación. Precisamente porque cuanto más conocido o divulgado, mejor cumple el rol de creador de mitos modernos que, para el caso español, parece que siguen siendo válidos. Es aquí donde entra, ofreciendo una explicación, el contexto posmoderno.

Sin establece tampoco ahora un linaje del término, no debería ser un problema asumir que postmodernidad implica una superación, el traslado a una posterioridad, de la modernidad ${ }^{30}$. La definición aplicada al caso de estudio se obtiene no tanto de las primeras teorizaciones sobre la posmodernidad (surgidas después de 1945) como de una serie de investigaciones que lleva tiempo sosteniendo la aparición, precisamente en la década de los treinta del siglo XX, de una contestación o cansancio ante la modernidad por parte de ciertos panoramas culturales que puede llamarse postmodernidad previa $^{31}$. Por ejemplo, en el citado catálogo sobre arte y poder en la Rusia soviética, se define el Realismo Socialista soviético en base a premisas que hoy se considerarían ciertamente posmodernas, asumiendo que la identidad de lo postmoderno se basa casi exclusivamente en su oposición/superación de lo moderno. Se afirma aquí sobre el realismo socialista: "no es un arte individual, sino colectivo - murales hechos siguiendo el método de brigada- o anónimo -incontables copias de las estatuas de Lenin en todas las ciudades de la URSS- (...) no es un arte de vanguardia con recursos claros, sino que produce modelos sintéticos y homogéneos, (...) era precisamente posmoderno avant la lettre ${ }^{32}$ ".

Estas definiciones pueden encontrase más que manifestados, hasta superados, en el fenómeno español de 1936-1939. Pero definir esta cuestión con claridad hasta poder comprobar la existencia de una condición posmoderna plausible para el imaginario

29 KRAUSS, Rosalind E., La originalidad de la vanguardia y otros mitos modernos, Madrid, Alianza, 1996; GIDDENS, Anthony, Consecuencias de la modernidad, Madrid, Alianza, 1999; SEBRELI, Juan José, El asedio a la modernidad: crítica del relativismo cultural, Barcelona, Ariel, 1992.

30 El obligatorio LYOTARD, Jean-François, La condición postmoderna: informe sobre el saber, Madrid, Cátedra, 1984; IGGERS, Georg G., Historiography in the twentieth century: from scientific objectivity to the postmodern challenge, Middletown, Wesleyan University Press, 2005; SMART, Barry, Modern conditions, postmodern controversies, London, Routledge, 1992; Idem, Postmodernity, London, Routledge, 1993.

31 BOIS, Yves-Alain, BUCHLOH, Benjamin H.D, KRAUSS, Rosalind E. y FOSTER Hal, Arte desde 1900: modernidad, antimodernidad, postmodernidad, Madrid, Akal, 2006; MILLER, Tyrus, Late Modernism: politics, fiction and the arts between the world wars, Berkeley, University of California Press, 1999; Idem, "Mímesis del hombre nuevo. Los años treinta: de la ideología a la antropolítica", en Encuentros con los años '30, Madrid, MNCARS/La Fábrica, 2012, pp. 89-95; RAMÍREZ DOMÍNGUEZ, Juan Antonio (1976), op. cit.

32 DEGOT, Ekaterina, "El Realismo Socialista desde el punto de vista de la crítica de arte", en $L a$ Caballería Roja, op. cit., p. 478. 
español es el objetivo de la tesis doctoral, por lo que en el marco de este artículo es suficiente con señalar estos ecos encontrados. De hecho, cada uno de ellos presenta un tema de estudio de bastante independencia, ya que no depende de un modelo tan dogmático como el soviético.

Sin embargo, ¿dónde queda la modernidad en España a partir de1936? El trastoque de los procesos habituales del mundo "cultural" sólo es el primer paso. A partir de ahí van desarrollándose circunstancias más o menos equivalentes a lo anteriormente citado sobre el caso soviético. En el imaginario español hay lugar para los artistas originales, pero la originalidad no es un valor en sí mismo: se mezclan artistas con amateurs en la elaboración de colectivos y obras ${ }^{33}$ mientras la circulación de las imágenes, a veces entre lenguajes distintos, es una realidad ${ }^{34}$. Los productos del imaginario español, aún liberados de la impuesta homogeneidad estalinista sin duda no son "vanguardia". Es más, su disposición en tan vasto conglomerado acaba difuminando de forma drástica las diferencias entre una cultura "elevada" y otra "popular" en el momento en que artistas (aquellos ya elevados a esa categoría social antes de julio del 36), estudiantes, obreros, especialistas, voluntarios y espontáneos se organizan e implican en la elaboración de infinidad de representaciones que ni se premian con largueza económica ni son realizadas pensando en posteridades o conservaciones museísticas. Al contrario, su función totalizadora y masiva, su acumulación en una hiperrealidad y su dependencia de la cosmovisión los alejan totalmente de los mitos "modernos" erigidos anteriormente en una realidad que, precisamente, está en plena subversión. Por lo tanto, ni su elaboración ni su consumo pueden compararse con lo que antes del verano del 36 se conocía como "arte".

Al mismo tiempo, se hacen sentir y escuchar grupos hasta entonces minoritarios, con sus correspondientes ecos en el imaginario ${ }^{35}$. La propia abundancia de ese imaginario, en la que todos los lenguajes empleados tienden a una igualdad de condiciones, supone una negación de la modernidad elocuente por sí misma. Si se toma como ejemplo la "propaganda de bulto", se observa que ésta bien puede, después de cumplir su uso efímero, fotografiarse para la portada de una publicación especializada lo mismo que servir de modelo para un óleo de los que se enviaron a la exposición universal de $1937^{36}$. La pregunta clave es si esta serie de cuestiones, que sin duda suponen una negación de la modernidad, conforman o no un verdadero modelo posmoderno. Verificar esta compleja circunstancia es labor de la conclusión de la tesis, aunque cabe apuntar ahora dos problemas: la coexistencia de varias cosmovisiones

33 CABAÑAS BRAVO, Miguel (2007), op. cit., pp. 110-111.

34 PÉREZ SEGURA, Javier, Rastreando algunos frentes del arte, en Revistas, Modernidad y Guerra, Madrid, Museo Nacional Centro de Arte Reina Sofía, 2008, pp. 39-52.

35 Por ejemplo, el batallón de jinetes gitanos organizado por Helios Gómez, en GÓMEZ PLANA, Gabriel, y MIGNOT, Caroline, Helios Gómez. La revolución gráfica, Barcelona, Associació Catalana d'Investigacions Marxistes, 2009, p. 149. Y, por supuesto, el papel activo de la mujer, sin precedentes hasta entonces en España, personificado tanto por milicianas como Mika Etchebéhère: MERA, Cipriano (2006), op. cit., pp. 152,195 y 197; como por la labor de la asociación Mujeres Libres: NASH, Mary (ed. y pról.), Mujeres Libres: España, 1936-1939, Barcelona, Tusquets, 1975; ACKELSBERG, Martha A., Mujeres Libres: el anarquismo y la lucha por la emancipación de las mujeres, Bilbao, Virus, 1999.

36 PÉREZ SEGURA, Javier (2008), op. cit. 
(PCE, POUM, PSUC, PSOE, CNT...) obligada por las circunstancias alimenta ciertas mitologías de exclusividad en la originalidad de la representación y conformación de la realidad, que dificultan la independencia total de la modernidad del imaginario español, precisamente por la validez de unos mitos esencialmente modernos. Eso, por un lado. Por el otro, está la espinosa y evidente cuestión del "compromiso". Si se supone que el desapego producido por el escepticismo ante los mitos modernos desvincula el lenguaje posmoderno posterior a 1945 de cualquier cosmovisión o "ismo", ¿qué decir de la situación española, en la que el principio y el final del imaginario localizado son los impulsos de las cosmovisiones, que se trata en realidad de una situación a-moderna?

Es lógico que para dirimir cuestiones de tal envergadura sea necesaria una tesis doctoral. Es suficiente con que resulte identificable, de momento, cierta huella de posmodernidad en el fenómeno español. Y dadas las circunstancias recién descritas, las posibilidades, aún con las contradicciones que presenten, merecen un análisis en profundidad.

\section{Descripción sumaria de la metodología resultante}

Entonces, con la dificultad que presentan conceptos tan cargados de significado, ante la compleja, profunda y desconocida naturaleza del imaginario español, y con la intención de identificarlo, catalogarlo, obtener una estructura de sus representaciones, para por último observarlo a la luz de una condición posmoderna, ¿qué tipo de análisis se requiere? No puede ser una metodología historiográfica al uso, ya que se ha visto que resulta insuficiente en los términos que plantea. Lo mismo puede decirse para la historia cultural o la historiografía artística. Y es que el fenómeno español ramifica sus implicaciones en muy diversos ámbitos del conocimiento. El imaginario responde más a la naturaleza de las mentalidades de su coyuntura espaciotemporal (su momento histórico), lo que lo enlaza con una obligada perspectiva sociológica que sitúe a la población que lo experimentó en su lugar correspondiente, al mismo tiempo que al tratarse de un imaginario desplegado en muchos tipos de lenguaje se hace necesario un análisis iconográfico -aún que el fenómeno se componga de manifestaciones no visuales.

Por otra parte, si se considera cada elaboración del imaginario como un gran signo formado por más signos, con categoría simbólica y significado concreto, su investigación, siendo teóricamente ortodoxos, puede dividirse en dos momentos. Comienza con un análisis semántico que analiza los componentes del imaginario en base a su origen, es decir, desde las cosmovisiones que lo determinan, y termina con un análisis que indague sobre el efecto del imaginario hacia sus espectadores (consumidores, participantes... $)^{37}$. Una vez el desarrollo de la tesis doctoral haya analizado el sufi-

37 Insistiendo en que sólo es la manera más estrictamente ortodoxa de expresarlo, que posteriormente se ajustará a las necesidades concretas de la investigación, ECO, Umberto, Signo, Barcelona, Labor, 1976, p. 28, cit. RAMÍREZ DOMÍNGUEZ, Juan Antonio (1976), op. cit., pp. 300-301; ECO, Umberto, Apocalipticos e Integrados, Barcelona, Lumen, 1968. 
ciente número de signos que componen el imaginario y su simbología específica, podrán observarse como parte de un lenguaje global (una estructura global, si se quiere) cuya traducción supondrá una comprensión mucho más directa, primero, del imaginario como fenómeno específico, pues se podrá identificar cada signo en su símbolo/ significado correspondiente. Y segundo, de la comunicación entre el imaginario y la sociedad en la que se desarrolla. Este aspecto es quizá el más importante, pues permite obtener un mapa de significados sin precedentes para comprender la España del 36 al 39 que resulta más elocuente sobre las motivaciones últimas de los españoles que la experimentaron. Precisamente gracias a su desarrollo como súper-lenguaje, pues apela a un imaginario (compuesto de infinidad de representaciones construidas a su vez en base a la suma y combinación de signos y símbolos en dinamización perpetua) que determina, además de la guerra, todo aquello que se pretende realidad.

De la combinación de una metodología como esta para la investigación de un fenómeno tan mal conocido puede salir resultante el conocimiento de los valores arquetípicos del fenómeno, pues a fin de cuentas el imaginario es para la sociedad modelo y construcción visible de la cosmovisión.

Ello hace, en definitiva, que la tesis iniciada constituya una investigación necesaria que permita comprender las implicaciones más decisivas de algo totalmente fundamental en la identidad de la sociedad española, cuyas influencias llegan a la actualidad sin que se les preste la suficiente atención.

\section{Recapitulación a modo de conclusión}

De hecho, tan fundamental que, como hemos señalado, está sujeto aún a varios desequilibrios: entre su verdadera identidad y la pervivencia de mitos que la pervierten; entre los términos que designan sus circunstancias y la realidad que ocultan, etcétera. Se hace necesario un ajuste terminológico y teórico que ofrezca mayores posibilidades de discernir la totalidad del fenómeno. Empezando por dudar de los conceptos que lo describen habitualmente, desde la denominación general de "guerra civil" hasta las definiciones de su rol cultural como dependientes de una u otra "ideología" y elaboradoras de una acción de "propaganda", se han propuesto como alternativas los términos "cosmovisión", "hiperrealidad" e "imaginario" por considerar que expresan de forma mucho más clara sus complejidades y contradicciones.

Una vez observada la relación entre dichos términos, se ha considerado la cantidad de manifestaciones del imaginario en cuanto a la idea de "cultura" y "arte" en el desarrollo de lo que se conoce como "modernidad", para concluir que su identidad no puede describirse según las categorías artísticas y culturales habituales de la historiografía. La condición particular del imaginario acerca más su identidad a una estructura global en la que se insertan diversos productos "culturales", "artísticos" o no, que a un hecho que forme parte de la historia cultural canónica (académica o alternativa) del siglo XX. Es un hecho muy específico, enraizado en las consecuencias de unas cosmovisiones que lo sitúan mucho más allá de una mera construcción cultural, debido en gran parte a la conformación de hiperrealidad que lleva a cabo. Al contrario, 
su verdadera situación se encuentra más en una cierta condición postmoderna que habrá que localizar y definir pertinentemente. Para ello se propone una metodología principalmente semiótica que también atiende a las implicaciones sociológicas y simbólicas del imaginario, para la que todas las manifestaciones producidas por éste son signos cuyo lenguaje correspondiente permitirá, al ser establecido como tal, conocer el alcance de las motivaciones que llevaron a la población española a la situación más dramática de su contemporaneidad. 